\title{
Ontario minister says doctors among those to blame for cut in special diet allowance
}

Published at www.cmaj.ca on Apr. 8

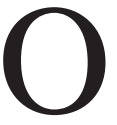
ntario's Minister of Community and Social Services is pointing to doctors and other health care professionals who filled out forms to get a special diet allowance for welfare recipients as one of the reasons the province cut the ballooning program.

"This program is not achieving its intended results," Madeleine Meilleur says. "It's increasing every year, and there's no end to it."

In its blueprint for fiscal 2010/11, Ontario announced that it would end the program, which served 136250 people on welfare and disability support. Although the program could pay $\$ 250$ a month in supplements for people with such medical conditions as food allergies, celiac disease and diabetes, or provide fruit and vegetables for pregnant or nursing mothers, it typically paid much less. To receive the allowance, people had to get a doctor, nurse or dietitian to fill out a form, which they submitted to their welfare or disability worker.

The program cost $\$ 220$ million in fiscal 2009/10, up from $\$ 6$ million in $2001 / 02$, and was projected to rise to $\$ 750$ million by fiscal $2015 / 16$.

Meilleur noted that a 2009 auditor general's report criticized doctors and poverty advocates who organized clinics to help hundreds of social assistance recipients get their dietary allowance forms filled. The report "raised the concern about the fact that some people are abusing the program and doctors - not just doctors but health care professionals - are signing these forms without a proper examination of the client. We have a responsibility as a government to families and to taxpayers to provide fair, accountable, sustainable government, and this one (program) is not accomplishing this."

The province intends to replace the diet allowance with a "nutritional sup-

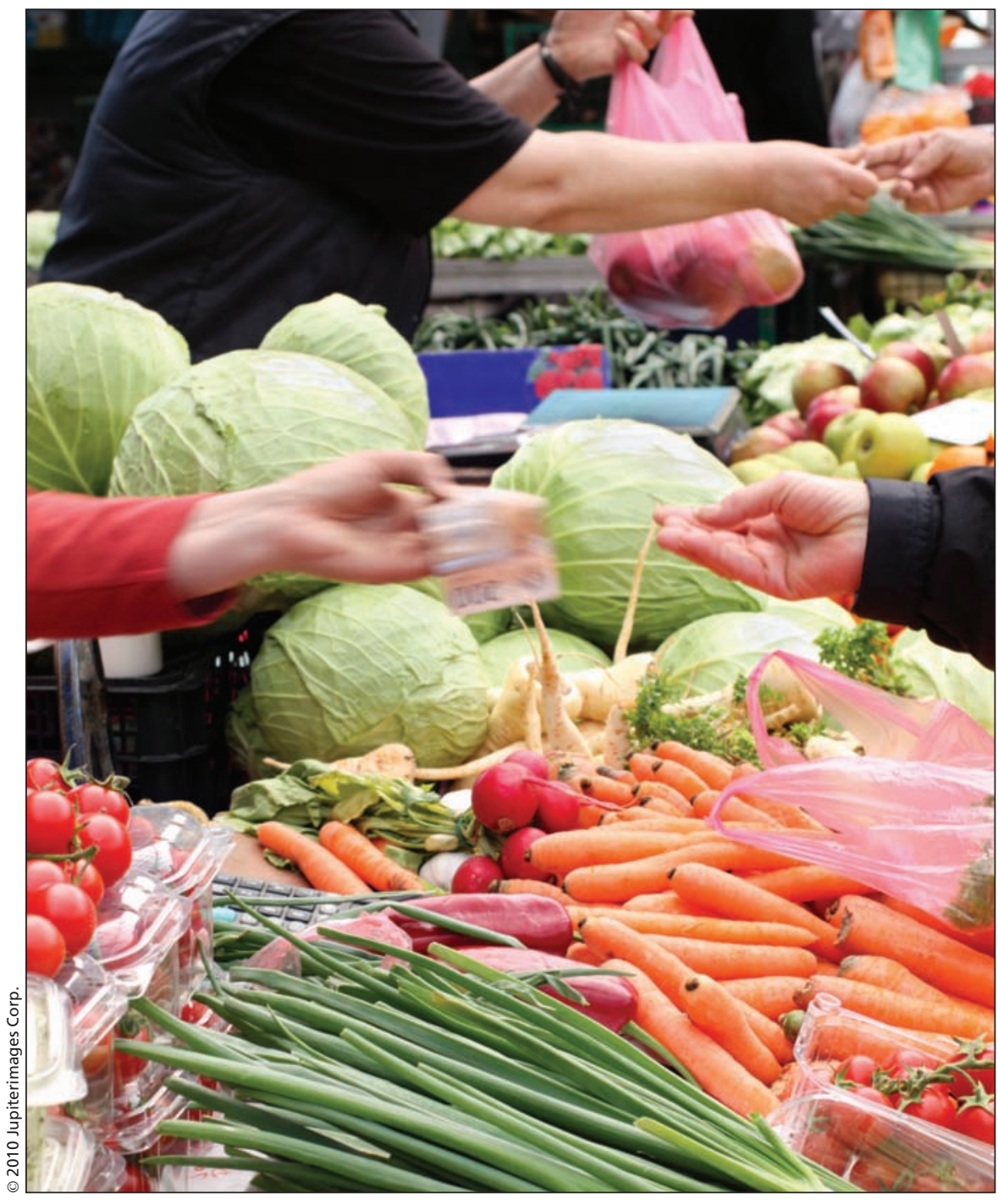

Ontario's discontinued special diet allowance program provided up to $\$ 250$ per month for people with medical conditions, pregnant women or nursing mothers to purchase fruits and vegetables.

plement" plan that the Ministry of Health and Long-Term Care, rather than social services, will administer.

Although the nutritional supplement plan has not yet been developed, it "will be a lot narrower," Meilleur says. "I believe fewer patients will be able to access it, so the program will be for severe cases. At the beginning, I'm sure it will cost less."
The province's decision has angered some doctors, nurses and other health care professionals, who are calling on their associations and the public to mobilize.

"It's completely unconscionable," says Dr. Gary Bloch, a family physician with St. Michael's Hospital in Toronto, Ontario, and a member of Health Providers Against Poverty. 
"It significantly impacts the potential for people with disabling medical conditions to improve their health. This supplement has been a lifeline for a lot of my patients who live on welfare," Bloch says.

Health Providers Against Poverty, Health for All and the Registered Nurses Association of Ontario are urging health providers and their associations, including the Ontario Medical Association, to press for a joint meeting with the minister of health and longterm care, during which they plan to demand that the diet allowance be reinstated or transformed into a "robust" program.

"If there was a new law that allowed smoking in restaurants again, you would find doctors standing up all over the place and denouncing that," says Bloch. "We should be taking the same type of approach to this."

A spokesperson said the Ontario Medical Association had "no position" on the issue.
But physicians and nurses say cutting the program will eventually increase the cost of treating illnesses that could have been prevented or alleviated by a healthier diet for welfare recipients.

"I don't think it's cost-effective," says Dr. Michaela Beder, a member of Health for All and Health Providers Against Poverty. "We're actually going to see worsening of health conditions, which will lead to further costs."

Although Meilleur agrees with health care professionals about the link between diet and health, she says the special diet allowance should not be used to defray the costs of regular food. Meilleur adds that the medical community will be involved in designing the new nutritional supplement program.

Doris Grinspun, executive director of the Registered Nurses Association of Ontario, says the nurses have protested the decision to Ontario Health Minister Deb Matthews.
Grinspun hopes Matthews will take advantage of the prevention mandate of her ministry to institute a new program that will help reduce poverty. "Social assistance rates are not keeping up at all with a liveable income," she says. "This is not about extreme cases of people with illnesses. This is about extreme cases of poverty where illness compounds the situation."

If the province wants to eliminate the diet allowance completely, it should raise the overall welfare and disability payments by $4 \%$, rather than $1 \%$, Grinspun says.

British Columbia, Alberta, Saskatchewan, Manitoba, New Brunswick, PEI, Newfoundland and Labrador, Nova Scotia and the Yukon all offer some form of diet or nutritional supplement to welfare recipients, although Ontario's program was by far the most generous. - Laura Eggertson, Ottawa, Ont.

DOI:10.1503/cmaj.109-3232 